\title{
Hospital case-mix funding and the necessity to adjust for socio-economic status Julian Perelman
}

Address: National School of Public Health, Nova University of Lisbon, Avenida Padre Cruz, Lisbon, 1600-560, Portugal

Email: Julian Perelman - jperelman@ensp.unl.pt

from 24th Patient Classification Systems International (PCSI) Working Conference

Lisbon, Portugal. 8-II October 2008

Published: 27 November 2008

BMC Health Services Research 2008, 8(SuppI I):A7 doi:10.1 I86/I472-6963-8-SI-A7

This abstract is available from: http://www.biomedcentral.com/I472-6963/8/SI/A7

(c) 2008 Perelman; licensee BioMed Central Ltd.

\section{Introduction}

Although the efficacy of hospital case-mix funding in reducing resource use has been largely documented (at least in the short term), many debates persist as regards its consequences on equity. Several authors have pointed to the failure of risk-adjustment methods to accurately reflect the patient's condition and needs, raising the threat of patient selection and unfair penalization of hospitals. Most of this debate has centered around the failure to riskadjust for the severity of disease, pointing to the drawbacks of diagnosis classification systems. In this paper, we emphasize the importance of the patient's socio-economic status (SES).

The case of Belgium is an interesting example of this riskadjustment debate. Simply put, the Belgian system consists of paying in-patient services a per diem for a normative number of in-patient days based on the patient's characteristics (AP-DRG, age and hospitalization, or not in a geriatric ward). The hospitals with "excess days" with respect to the norm are financially penalized, while the others are financially rewarded. On the one hand, the "pro-SES" argue that the AP-DRG/age classification system is limited in predicting the differences in length of stay between poorer and richer patients. Hence, hospitals with a large proportion of underprivileged patients are unfairly penalized, while other hospitals receive windfall gains. Meanwhile, the failure to adjust payments to patients' SES rewards hospitals practicing "case selection" while punishing hospitals doing well in treating the poor. On the other hand, the opponents contend that the socio- economic condition is accounted for by severity indicators, particularly since the shift from AP- to the "refined" APR-DRGs.

In 2007, the Belgian government decided to adopt a series of socio-economic characteristics as risk-adjustors, starting from the 2008 financing. In this paper, we present the evidence that sustained this decision.

\section{Methods}

We use a database that includes all in-patient stays for 60 Belgian hospitals for the 2002-2003 period. This database is used by the Ministry of Public Health for financing, administrative, and medical purposes (records are equivalent to the US Medical Data Base System). The database contains 673,407 overnight in-patient stays. Its data includes fully comparable information on patients' clinical and demographic characteristics. Those data are merged with additional data from the six Belgian sickness funds, which provide information on patients' economic situations. A large array of socio-economic indicators, based on the patient's neighborhood of residence, are also used as a proxy of the individual's socio-economic status and to account for potential contextual effects.

\section{Results}

We show that low-SES patients have a significantly longer length of stay. The beneficiaries of reduced co-payment rates stay $15 \%$ longer at the hospital and the recipients of health services vouchers $24 \%$ longer (both statuses are attributed to low-income people). People living alone stay 
$5 \%$ longer, as do people living in underprivileged neighborhoods, defined by the high rate of unemployment, the low median income, the low percentage of car owners and the poor quality of housing. In addition, we find evidence that the impact of SES persists while controlling for APRDRGs. Finally, we show how the financing formula used by policy-makers has been built in practice, and how it decreases the incentives for risk-selection and penalizes hospitals treating a high percentages of low-income people.

\section{Conclusion}

Our findings show the specificity of SES as a predictor of length of stay. That is, the impact of SES remains significant and large in magnitude after a more accurate control for the severity of disease. This finding also highlights that heterogeneity is still large within diagnosis categories even after the shift towards APR-DRGs. The importance of these results should not be neglected when designing hospital financing schemes; otherwise, the search for a higher efficiency might have unintended effects on equity in access and use of in-patient care.
Publish with Biomed Central and every scientist can read your work free of charge

"BioMed Central will be the most significant development for disseminating the results of biomedical research in our lifetime. " Sir Paul Nurse, Cancer Research UK

Your research papers will be:

- available free of charge to the entire biomedical community

- peer reviewed and published immediately upon acceptance

- cited in PubMed and archived on PubMed Central

- yours - you keep the copyright

Submit your manuscript here:

http://www.biomedcentral.com/info/publishing_adv.asp 